\title{
Spectrum of Quality of Life after Valve Surgery in Patients with Rheumatic Heart Disease.
}

\author{
Dikshya Joshi', Anushruti Shrestha², Minani Gurung ${ }^{3}$, Navin C Gautam¹, Yogeshwor M. Singh', \\ Apurba Thakur', Nishes Basnet', Rabindra B. Timala'.
}

${ }^{1}$ Department of cardiac surgery, Shahid Gangalal National Heart Centre.

${ }^{2}$ Third year medical student, Nepal Medical College.

${ }^{3}$ Department of Public Health, Nepal Institute of Development Studies.

\section{Corresponding Author:}

Dikshya Joshi

Department of cardiac surgery, Shahid Gangalal National Heart Centre.

E-mail: drdixajoshi@gmail.com

ORCID ID: 0000-0002-1031-325X

Cite this article as: Joshi D, Shrestha A, Gurung M, et al. Spectrum of Quality of Life after Valve Surgery in Patients with Rheumatic Heart Disease. Nepalese Heart Journal 2021; Vol 18 (1): 53-56.

Submitted date: $29-12-2020$

Accepted date: $27-02-2021$

\section{Abstract}

Background and Aims: Improvement in quality of life is one of the principal goals of valve surgery. The purpose of this study was to assess the quality of life in patients living with mechanical heart valves.

Methods: We conducted a cross-sectional descriptive study among 131 (42 Males, and 89 Female) patients, who had undergone valve procedures at different times in clinic visit of department of cardiac surgery, unit I of Shahid Gangalal National Heart Centre from August 1 till August 29, 2019. Quality of life index was measured using Ferrans and Power quality of life index, cardiac version IV via written questionnaire or verbal interview.

Results: Mean age was $40.57 \pm 1.4$ (16-75) years. Mean duration of follow up was $4.68 \pm 4.03$ years ( 3 months to 18 years). Subjects reported the lowest quality of life scores in the health and functioning domain prior to surgery (15.61 \pm 1.30 ), which improved $47.15 \%$ after surgery (22.95 \pm 0.45$)$, psychological/spiritual domain improved $16.68 \%$, social and economic domain $26.24 \%$, family domain $11.49 \%$, with overall improvement $28.62 \%$. Women had significantly lower mean overall quality of life index (22.99 \pm 03.58$)(95 \%$ confidence interval 22.24-23.75) compared to male counterparts $(24.21 \pm 4.11)(95 \%$ confidence interval $22.92-25.49)(\mathrm{p}<0.05)$. Family domain had the highest score at the latest follow up (28.84 1.63$)$. There was a statistically significant correlation between the duration of operation and overall quality of life index (Pearson's rho 0.217, $\mathrm{p}<0.01$ ). There was no significant difference with the patients' age. Conclusion: This study confers significant improvement of quality of life after valve surgery with time. Age does not appear to limit the quality of life. Family support seems to be the biggest strength in our population.

Keywords: Quality of life; Quality of life index; QLI; Valve Surgery.

DOl: https://orcid.org/10.3126/njh.v18i1.36786

\section{Introduction}

Heart valve replacement surgeries have advanced with an experience of more than three decades, becoming one of the safest and routinely scheduled heart procedures. Regardless of improvements in materials and design, valves used for replacements are far from ideal, and life-long anticoagulation remains mandatory for mechanical valves. ${ }^{1}$ Parallel to decrease in the operative mortality, the potential quality of life for survivors has been becoming increasingly important in evaluating the late results and in selecting the appropriate device for the given patient. ${ }^{1}$

The present study was undertaken to examine our experience with the implant of mechanical prostheses in patients with rheumatic heart disease, evaluating the long-term outcomes, with particular focus on the quality-of-life index.

Improvement in quality of life is one of the principal goals of valve surgery. Parallel to the decrease in operative mortality after heart valve replacement, the potential quality of life index (QLI) for survivors has been becoming increasingly important in evaluating the late results

(a) Nepalese Heart Journal. Nepalese Heart Journal retain copyright and works is simultaneously licensed under Creative Commons Attribution License CC - By 4.0 that allows others to share the work with an acknowledge of the work's authorship and initial publication in this journal 
and in selecting the appropriate device for the given patient.All factors that determine the QLI are strongly affected after the valve replacement surgery in long run, which is reflected by return to normal daily activities, maintain self-esteem and keep normal relationships at work, in the community and at home.

\section{Materials and Methods}

After obtaining written approval from the Institutional Review Board, SGNHC/IRB No. 16-2020, all patients who had undergone valve procedures at different times, and those who visited in clinic visit of department of cardiac surgery, unit I of Shahid Gangalal National Heart Centre from August 1 till August 29, 2019 were asked if they were willing to provide the information for the study. A cross-sectional self-assessment of QLI, demographic characteristics and cardiovascular health history were recorded. QLI was measured using Ferrans and Power QLI, cardiac version IV via written questionnaire on follow up in outpatient department. The patients who visited for follow-up and in the PT-INR clinic were handed written questionnaires. The questionnaires had been translated to Nepalese language. The translated questionnaires were validated by forward and backward translation to maintain equivalence of the test questionnaire in the target language. Each patient was then interviewed by trained personnel. Scores before and after the procedure were asked and noted. Each patient was given around 10 minutes of time.

A total of 131 (42 Males, and 89 Female) patients, who had undergone valve procedures participated in our study. Demographic characteristics, cardiovascular health history was recorded, and QLI was measured using Ferrans and Power quality of life index, cardiac version IV via written questionnaire or verbal interview to those who gave consent for the study. Written consent form in local language was obtained from the participants.

\section{Sample Size Calculation}

The sample size was determined using the formula,

$$
\text { (n) }=\frac{\left(\mathrm{z}^{2} \mathrm{pq}\right)}{\mathrm{d}^{2}}
$$

where, $z=$ standard normal variate with value 1.96 at $95 \%$ confidence interval, $\mathrm{p}=$ Prevalence $=50 \%, \mathrm{q}=1-\mathrm{p}=1-0.5=0.5$, and $\mathrm{d}=$ allowable error, taken as $1 \%$. The sample size calculated was 96 . Taking nonresponse rate of $15 \%$, the total calculated sample size was 110 . The study population were selected conveniently from OPD. Altogether, 131 participants were included in our study.

The questionnaires, subscale items, scoring description and computer syntax was downloaded from the official website (http://qli.org.uic.edu) of Ferrans and Power QLI, cardiac version IV, after receiving consent via email from the original investigators who formulated the index. Patients were asked to complete the preoperative and postoperative questionnaires that were translated in local language to assess QLI. This survey asked people the simple question of how satisfied they are with their life in general. The QLI measures both satisfaction and importance regarding various aspects of life. The QLI produces five scores: QLI overall and in four domains (health and functioning, psychological/spiritual domain, social and economic domain, and family). Scores of QLI range from 0-30, which facilitates comparison of different findings, and higher scores indicated higher QLI. We analyzed the QLI in all five scales. The data was entered and analyzed systematically using Statistical Package for Social Sciences (SPSS) version 16. (SPSS Inc., Chicago, USA). All data were presented as frequency distribution and simple percentages. Descriptive statistics were presented in the form of mean \pm SD for all continuous variables. A $p$ value of $<0.05$ was considered to be statistically significant.

\section{Results}

The mean age of the study patients was $40.57 \pm 1.4$ (16-75) years. The study consisted of $82(62.6 \%)$ patients with Mitral Valve replacement, 18 (13.74\%) with Aortic Valve replacement, 31 (23.66\%) with Double Valve replacement, 37 (28.24\%) underwent concomitant Tricuspid repair (Table 1).

Table 1. Demographics and patient characteristics, $n=131$

\begin{tabular}{|ll|}
\hline $\begin{array}{l}\text { Demographics and Patient } \\
\text { Characteristics }\end{array}$ & Number \\
\hline Age, years (Range) & $40.57 \pm 1.4(16-75)$ Years \\
\hline Gender, Male & $42(32 \%)$ \\
\hline Female & $89(67.9 \%)$ \\
\hline Mitral Valve Replacement & $82(62.5 \%)$ \\
\hline Aortic Valve Replacement & $18(13.7 \%)$ \\
\hline Double Valve Replacement & $31(23.6 \%)$ \\
\hline Concomitant Tricuspid Repair & $37(28.2 \%)$ \\
\hline
\end{tabular}

Mean of overall QLI was assessed which was $23.39 \pm 3.79$ on a scale from $0-30$, for which higher scores indicated higher quality of life. QLI improved with the duration of time. There was statistically significant correlation between the duration of operation and overall QLI (Pearson's rho² 0.217, $\mathrm{p}<0.01$ ). Age did not appear to limit the QLI, as there was no statistically significant difference in QLI between different patients' age.

Mean duration of follow up was $4.68 \pm 4.03$ years ( 3 months to 18 years). The overall change in percentage before and after the procedure were $28.62 \%$ in overall QLI, $47.15 \%$ in the health and functioning domain, psychological/spiritual domain improved $16.68 \%$, social and economic domain $26.24 \%$, and family domain improved $11.49 \%$. Subjects reported the lowest quality of life scores in the health and functioning domain prior to surgery $(15.61 \pm 1.30)$, which improved $47.15 \%$ after surgery $(22.95 \pm 0.45)$, which is the most significant improvement that we can see among all other domains. Family domain had the highest score at the latest follow up (28.84 \pm 1.63$)$. Family support seems to be the biggest strength in our population (Figure 1). 
Figure 1. Mean Quality of Life Index.

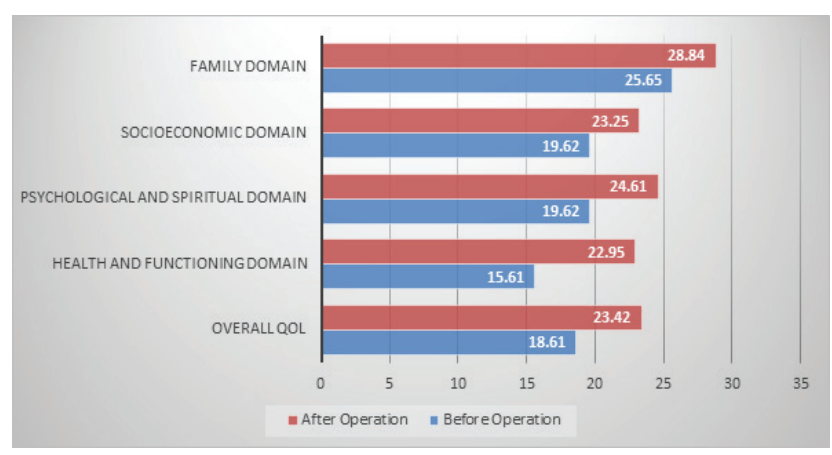

Women had significantly lower mean overall quality of life index (22.99 \pm 03.58$)(95 \%$ confidence interval 22.24-23.75) compared to male counterparts $(24.21 \pm 4.11)(95 \%$ confidence interval $22.92-$ 25.49) $(\mathrm{p}<0.05)$ (Figure 2).

Figure 2. QLI comparison between male and female.

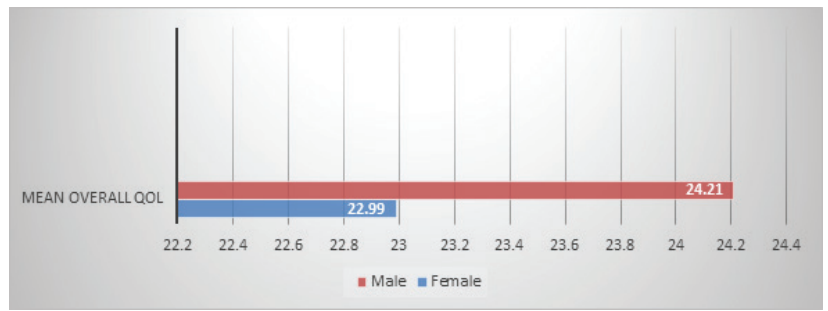

There was a statistically significant correlation between the duration of time after surgery and overall QLI (Pearson's rho 0.217, $\mathrm{p}<0.01$ ). There was no significant difference with the patients' age.

\section{Discussion}

The core finding of the study verified that QLI in patients improved after valve replacement for rheumatic heart disease. The full benefits of surgery can only be achieved when the patient's QLI and psychological status are maintained. This research is exclusive as this is the first of its kind in our part of population, with rheumatic heart disease.

A research by Walter PJ, Mohan R, et. al, tilted 'Quality of life after heart valve replacement' stated that the patient, can return to normal activities, maintain self-esteem and keep normal relationships at work, in the community and at home. Psychoneurological dysfunction was also found to decrease greatly within six months, although more than a quarter of patients were depressed preoperatively because of their disease. Overall, the experience was generally satisfying. ${ }^{1}$ Another study, a prospective study of changes in patients' quality of life after aortic valve replacement, by Goldsmith IR et.al. also had a comparable finding. All patients showed significant improvement in all eight QLI parameters. there was significant improvement in patients' QLI at three months after AVR, regardless of the type of aortic implant used; improvement was greatest in those aged $<70$ years. $^{2}$ Parviz Namazi ${ }^{3}$ et.al. also concluded that surgery not only is recommended to relief symptoms, but also can be considered as an effective strategy to improve QLI in patients with valve disease.
The debate about the choice of the ideal valvular prosthesis for patients is still ongoing, as the replacement devices are still far from ideal. ${ }^{1,4}$ Many authors support the implant of bio prostheses to avoid the risks related to lifelong oral anticoagulation. Elderly people receiving stentless bioprosthesis benefit emotionally because of avoidance of anticoagulation. ${ }^{5}$ Others prefer the use of mechanical prostheses to reduce the risk of reoperation for bioprosthetic structural deterioration. ${ }^{6}$ Another comparison study depicted that the use of tissue valve implants versus mechanical valve implant has little influence on improvement in quality of life at 18 months following aortic valve replacement. ${ }^{6}$ Despite improvement in the last few years, life-long warfarin is mandatory for mechanical valves. It should be stressed that in our study, most patients referring for cardiac procedures are often young (mean age of $40.57 \pm 1.4$ (16-75) years at the time of their latest follow-up), physically active and had mechanical valves implanted.

Improvement in quality of life is considered to be one of the principal goals of valve surgery. ${ }^{7}$ In our study, there was statistically significant improvement in all the domains of QLI. The overall change in percentage before and after the procedure were $28.62 \%, 47.15 \%$ in the health and functioning domain, psychological/spiritual domain improved $16.68 \%$, social and economic domain $26.24 \%$, and family domain improved $11.49 \%$. Family domain had the highest score at the latest follow up $(28.84 \pm 1.63)$. In context of a developing country like Nepal, family support seems to be our biggest strength. The improvement was common in patients with all ages, and there was no significant difference with the improvement of QLI among different age groups. A study led by Artyom Sedrakyan, titled, 'Age Does Not Limit Quality of Life Improvement in Cardiac Valve Surgery' had notable conclusion that had similar findings to our study, which stated that among patients referred for cardiac valve surgery, age does not appear to limit the QLI benefits of surgery. ${ }^{6}$ Another study led by Lee BY, titled 'Quality of life after aortic valve replacement' had a similar finding, which states that AVR appears to significantly improve the QLI of survivors, including those older than 70 years of age and even decades after the procedure, QLI remains high. The elderly may gain as much QLI benefit as younger patients. No consistent differences in resulting total QLI have been observed between mechanical and bioprosthetic valves. ${ }^{6}$ Yet another study following aortic valve replacement, about the octogenarians concluded that despite a more compromised pre-operative status showed an improvement in symptomatology, physical ability and general wellbeing, of a similar magnitude to that of the younger patients' group. These findings lend further support to the recommendation that valve replacement should be performed in octogenarians with symptomatic aortic stenosis. ${ }^{9}$

In this study, we found that improvements in overall QLI had significant correlation between the duration of operation following valve replacement. Our results are generally consistent with and extend the findings of previous studies that have examined QLI scores in patients receiving valve implants, and made comparisons of preoperative and postoperative. Sedrakyan and Hebert ${ }^{10}$ also demonstrated that there were improvements in overall QLI from the baseline at 18 months following aortic valve surgery were similar in patients receiving tissue and mechanical valve implants.

Phillips and Lansky ${ }^{11}$ were the first to demonstrate that in both tissue and mechanical valve recipients, preoperative QLI scores were generally lower than in population norms, whereas by 6 months postoperatively, the scores had improved and approximated those of the general population. However, that study was small and had a low follow-up rate, which resulted in power limitations that prevented analyses by type of valve implant. 


\section{Limitations of the Study}

There are issues that should be considered in the interpretation of the results. Baseline QLI data were asked to the patients only after surgery. Patients were asked to report their QLI in the month before surgery and we do not expect there to be differential recall bias. We collected postoperative QLI assessments who came to clinic followup. However, patients, all of whom, died prior, or lost follow-up could not be included in the study. We did not have sufficient power to investigate mortality in this study, and also, we did not compare between types of surgeries and types of valves used. Finally, we determined QLI at $4.68 \pm 4.03$ years ( 3 months to 18 years) following surgery; however, longer-term follow-up is indicated. The effect of different valve operations, be it repair, reconstruction or replacement, all impact on postoperative QLI which has been studied only more recently. ${ }^{12}$ Further recommendation or study needs to be done for comparing QLI with other surgical procedures.

\section{Conclusion}

Our results emphasize the improvement of quality of life after valve surgery with time regardless of the patients' age. The results also suggest that family support seems to be the biggest strength in our population. Nevertheless, the values also indicate that continued efforts are needed to improve health and financial independence of patients' valve surgery.

\section{Conflict of Interest: None Acknowledgement: None}

\section{References:}

1. Walter PJ, Mohan R.A.,et al. Quality of life after heart valve replacement. J Heart Valve Dis 1992;1(1):34-41. https://doi.org/10.1007/BF00435439 PMid:1363775

2. Goldsmith IR, Lip GY, et al. A prospective study of changes in patients' quality of life after aortic valve replacement. J Heart Valve Dis. 2001;10(3):346-353.

3. Parviz N, Seyed S.H, et al. Health-Related Quality of life after Valve Replacement Surgery. J Client-Centered Nursing Care. 2015;1(2): 91-96.

4. Korossis SA, Fisher J, et al. Cardiac valve replacement: a bioengineering approach. Bio-medical Materials and Engineering. 2000;10(2):83-124.

5. Florath A.A, Rosendahl U, et at. Mid term outcome and quality of life after aortic valve replacement in elderly people: mechanical versus stentless biological valves. Heart. 2005;91(8):1023-1029. https://doi.org/10.1002/ccd.26400 PMid:26800644.

6. Mariano V, Alessandro D.C, et al. Quality of Life After Implantation of Bileaflet Prostheses in Elderly Patients: An Anticoagulation Work Group Experience. Annals of Thoracic Surgery. 2007 Aug;84(2):459-65.

https://doi.org/10.1016/j.athoracsur. 2007.04.063 PMid:17643615.

7. Artyom S, Viola V. Age Does Not Limit Quality of Life Improvement in Cardiac Valve Surgery. J American College of Cardiology. 2003; 42 (7):1208-1214. https://doi.org/10.1016/S0735-1097(03)00949-5

8. Bruce Y.L, Thomas G.G, et al. Quality of life after aortic valve replacement, Expert Review of Pharmacoeconomics \& Outcomes Research,2004, 4:3, 265-275.

https://doi.org/10.1586/14737167.4.3.265 PMid:19807309

9. Olsson H.J, Orth-Gomér K, A. et al. Quality of life in octogenarians after valve replacement due to aortic stenosis: A prospective comparison with younger patients, European Heart J. 1996; 17(4): 583-589. https://doi.org/10.1093/ oxfordjournals.eurheartj.a014912 PMid:8733092.

10. Artyom S, Patricia H, et al. Quality of life after aortic valve replacement with tissue and mechanical implants. J Thorac and Cardiovas Surgery. 2008; 128(2):266-272, ISSN 0022-5223, https://doi.org/10.1016/j.jtcvs.2003.12.014 PMid:15282464.

11. Phillips RC, Lansky DJ. Outcomes management in heart valve replacement surgery: early experience. J Heart Valve Dis.1992;1(1):42-50.

12. Diana A, Annika H, et al. Quality of life after aortic valve surgery: Replacement versus reconstruction. J thorac and cardiovasc surgery. 2011;142(2):e19-e24. https://doi.org/10.1016/j.jtcvs.2011.02.006 PMid:21450311 